\title{
Exploration of the Confined Aquifers in the Yuyao River Valley (Eastern China) Using Electrical Sounding Method
}

\author{
Yu Zhao ${ }^{1}$, Youcan $\mathrm{Yu}^{1 *}$, Yufan Shen ${ }^{1}$ \\ ${ }^{1}$ School of Civil Engineering, Chongqing University, Chongqing, 400045, China
}

\begin{abstract}
With abundant groundwater resources and obvious spatial distribution characteristics of confined aquifers, the Yuyao River valley is located in Ningbo, a coastal city in eastern China. It is greatly significant for studying the formation, movement and recharge of groundwater and establishing a sustainable groundwater management system to determine the spatial distribution of confined aquifers. In this paper, the spatial distribution of confined aquifers in the Yuyao River valley are studied by combining the symmetrical quadrupole electrical sounding method with hydrogeological data. Through analysis of the existing hydrogeological data, it is corroborated that there are sand gravel and round gravel confined aquifers in the study area. Then, the results of borehole-side electrical sounding measurements show that significant electrical differences are found among each rock-soil layer in the study area, and the resistivity of sand gravel and round gravel confined aquifers varies from 10 to $20 \Omega \cdot \mathrm{m}$. Finally, 77 symmetrical quadrupole electrical soundings on 5 lines were carried out perpendicular to the Yuyao River valley, and the data of electrical sounding were inverted and analyzed by the analysis software of GeoElectro. After calibration with boreholes, the confined aquifers in the study area were determined to be zonally distributed along the middle line of the valley, with buried depth ranging from -65 to $-25 \mathrm{~m}$ and width exceeding 1000 $\mathrm{m}$.
\end{abstract}

\section{Introduction}

Groundwater is an important part of water resources and has a close relationship with human society. Because of its stable water supply conditions and good water quality, groundwater has become an important source of water for agricultural irrigation, industry and urban life, especially in arid and semi-arid areas where surface water is scarce [1-2]. It should be noted that groundwater is in a state of overall balance. Overdraft and unreasonable utilization of groundwater often cause groundwater level to drop seriously, forming a large area of groundwater funnel [3]. In addition, the infiltration of industrial wastewater and domestic sewage will seriously pollute the groundwater source. Therefore, it is of great significance to systematically study the formation and types of groundwater, the distribution of groundwater and the implementation of sustainable management and protection measures.

In recent years, numerous researches on groundwater exploration have been carried out worldwide, some of them are practical and innovative, e.g., Ground Penetrating Radar (GPR) [4]; Vertical Electric Sounding (VES) [5-6]; Nuclear Magnetic Resonance (NMR) [7]. Each method has its own applicable environment and preconditions. Exploration should take into account the actual field survey environment, existing survey technology and equipment, measurement period and cost. According to recent studies, it is reasonable to detect the spatial distribution of confined aquifers in the Yuyao River Valley by using symmetrical quadrupole electrical sounding method combined with hydrogeological data.

\section{Methods}

\subsection{Hydrogeological data}

Geotechnical stratum is the site where groundwater exists. The groundwater content in different lithological strata is significantly different. In addition, the groundwater content is affected by the geotechnical porosity, specific yield, permeability coefficient, specific storage and other hydrogeological parameters. Determining the lithological characteristics and hydrogeological parameters of rock and soil layers in the study area is of great significance to the correct detection of groundwater distribution. In order to determine the lithology, distribution, depth and thickness of confined aquifers in the Yuyao River Valley, 13 boreholes (Fig. 1) and other hydrogeological data in the study area were collected and collated.

\subsection{Borehole-side electrical sounding measurements}

The electrical characteristics of rock and soil layers are

*Corresponding author's e-mail: Youcan Yu; email: $979831163 @ q q . c o m$ 
one of the key factors to measure whether resistivity sounding can be carried out in the study area. The resistivity of rock and soil layers is mainly controlled by their porosity, lithology and water content. The resistivity of rock and soil layers with different water content is also obviously different. In order to determine the electrical characteristics of rock and soil layers in the Yuyao River Valley, especially the resistivity of sand gravel and round gravel confined aquifers, the borehole-side electrical sounding measurements (Fig. 1) were carried out in October 2017 near 13 boreholes in the survey area, and symmetrical quadrupole device (A-MN-B) was used in all borehole-side electrical sounding measurements.

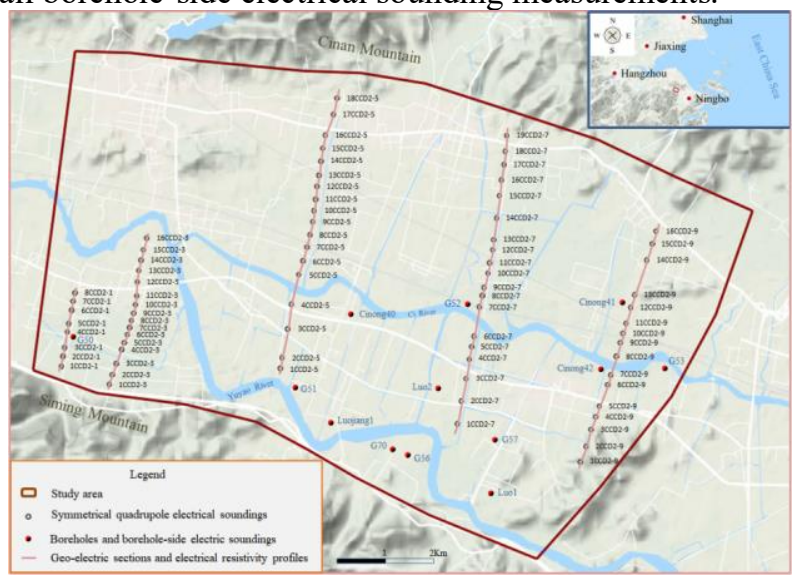

Figure 1. The location of symmetrical quadrupole electrical soundings and boreholes in the study area.

\subsection{Symmetric quadrupole electrical sounding}

In this study, the spatial distribution characteristics of confined aquifers in the Yuyao River Valley are determined by resistivity sounding method. In 2017, 77 electrical soundings were carried out on five surveying lines perpendicular to the Yuyao River Valley (Fig. 1), and symmetrical quadrupole device (A-MN-B) was used in all electrical sounding measurements. Influenced by the actual survey environment and topography, the length of symmetrical quadrupole electrical sounding is limited in the direction perpendicular to the valley. The electrical sounding exploration used the multi-function direct current instrument (DZD-6A) produced by Chongqing Geological Instrument Factory of China Geological Equipment Corporation. The steel electrode with length of $50 \mathrm{~cm}$ is used as the power supply electrode, and the copper electrode with lower polarization is used as the measuring electrode. According to the field conditions, the position of line and electric sounding point is determined by combining field survey with GPS-RTK. The running direction of each sounding point is along the direction of the line. The actual supply voltage is $400 \mathrm{~V}$, the supply time is $1 \mathrm{~S}$, and the distance between the supply electrodes gradually increases from $2 \mathrm{~m}$ to $500 \mathrm{~m}$. The collected field data of electrical sounding are inverted and interpreted by the geoelectric analysis software of GeoElectro. The interpretation of the results contributed to the construction of the symmetric quadrupole electrical sounding models, geo-electric sections and the electrical resistivity profiles.

\section{Results}

\subsection{Lithology}

Hydrogeological data in the study area show that the Quaternary sediments is unevenly distributed. The Quaternary thickness gradually increases from the mountainous on both sides to the middle of the valley, and the maximum thickness of the Quaternary sediments in the center of the valley can reach $60 \mathrm{~m}$. The lithology of rock and soil layers has obvious sedimentary characteristics. From top to bottom, the sequence is "fill silty clay - mucky silty clay - silty sand - medium-coarse sand - sand (round) gravel - bedrock". The boreholes in the survey area revealed that confined aquifers mainly exist in sand gravel and round gravel layers. According to the topographic features and paleosedimentary environment, the sand gravel and round gravel layers mainly distribute in middle center of the valley.

\subsection{Borehole-side electric sounding measurements}

In October 2017, borehole-side electrical sounding measurements were carried out in the study area. The original data of electrical soundings are inverted and interpreted by the geoelectric analysis software of GeoElectro, and the borehole-side electrical sounding inversion models are obtained.

The G52 borehole-side electrical sounding inversion model (Fig. 2a) can be generalized into five electrical layers (L1, L2, L3, L4 and L5) after calibration with G52 borehole. The resistivity of surface electrical layer L1 is $22 \Omega \cdot \mathrm{m}$ and its thickness is $1.0 \mathrm{~m}$, which corresponds to the miscellaneous fill. The low resistivity layer L2 is composed of six layers with a total thickness of $21.9 \mathrm{~m}$, corresponding to the silty clay and mucky silty clay. The electrical layer L3 with $11 \Omega \cdot \mathrm{m}$ and $14 \mathrm{~m}$ of thickness corresponds to the silty sand. The electrical layer L4 with the resistivity of $19 \Omega \cdot \mathrm{m}$ and $16 \mathrm{~m}$ of thickness corresponds to the round gravel confined aquifer, covering on the resistant substratum L5 of intermediary weathered mudstone.

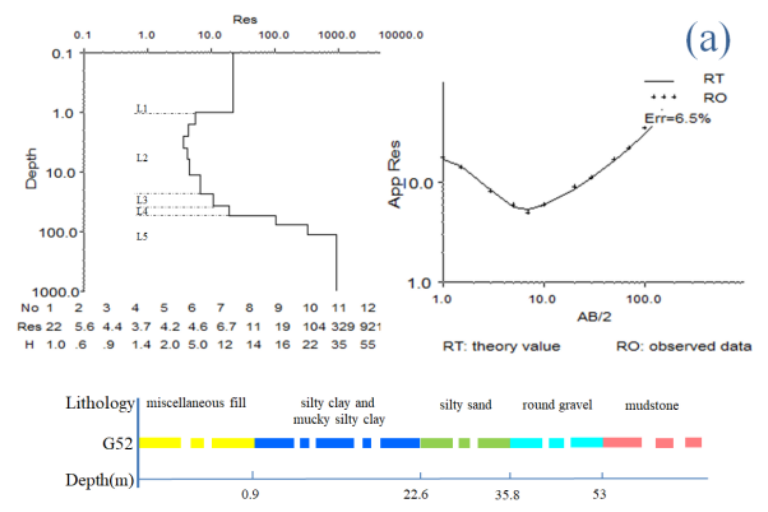




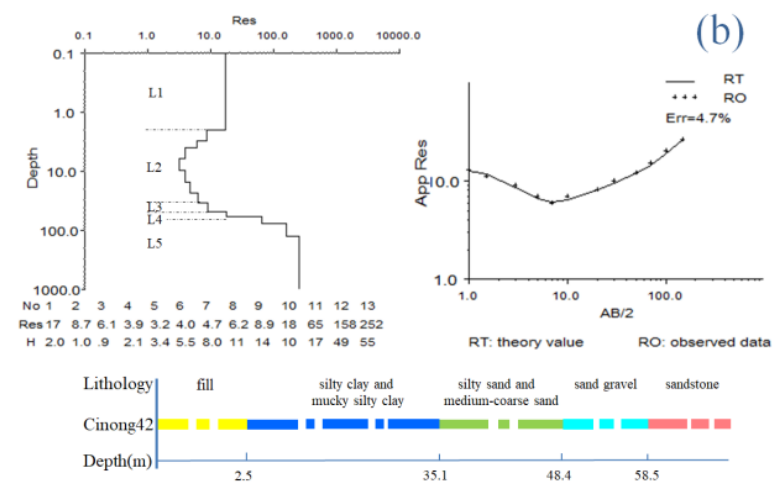

Figure 2. Borehole-side electrical sounding inversion model a) G52 and b) Cinong42. fitting accuracy of $4.7 \%$, and it can be interpreted as five electrical layers (L1, L2, L3, L4 and L5) after calibration with Cinong 42 borehole. The resistivity and thickness of the top layer $\mathrm{L} 1$ are $17 \Omega \cdot \mathrm{m}$ and $2.0 \mathrm{~m}$ respectively, corresponding to the fill. The electrical layer L2 consists of seven low resistivity layers with a total thickness of $31.9 \mathrm{~m}$, corresponding to the silty clay and mucky silty clay. The resistivity of L3 layer is $8.9 \Omega \cdot \mathrm{m}$ and its thickness is $14 \mathrm{~m}$, which corresponds to the silty sand and medium-coarse sand. The electrical layer L4 has a resistivity of $18 \Omega \cdot \mathrm{m}$ and a thickness of $10 \mathrm{~m}$, corresponding to the sand gravel confined aquifer. The resistivity of sandstone high resistivity layer L5 is not less than $65 \Omega \cdot \mathrm{m}$.

The Cinong 42 borehole-side electrical sounding inversion model (Fig. 2b) consists of 13 layers with a

Table 1 . The corresponding relationship between formation lithology and resistivity in the study area.

\begin{tabular}{ccc}
\hline Formation age & Lithology & Resistivity $(\Omega \cdot \mathrm{m})$ \\
\hline $\mathrm{Q}_{4}$ & fill and silt & $0.5 \sim 150$ \\
$\mathrm{Q}_{4} 、 \mathrm{Q}_{3}$ & silty clay and mucky silty clay & $0.5 \sim 8$ \\
$\mathrm{Q}_{3} 、 \mathrm{Q}_{2}$ & silty sand, fine sand and medium-coarse sand & $4 \sim 15$ \\
$\mathrm{Q}_{3} 、 \mathrm{Q}_{2}$ & sand gravel and round gravel & $10 \sim 20$ \\
$\mathrm{~K}_{1 \mathrm{c}}$ & argillaceous siltstone and mudstone & \\
$\mathrm{K}_{1 \mathrm{c}}$ & tuffaceous sandstone & $60 \sim 2000$ \\
$\mathrm{~K}_{1 \mathrm{t}}$ & lava tuff breccia and limestone & \\
$\mathrm{K}_{1 \mathrm{x}}$ & siltstone and sandstone & \\
\hline
\end{tabular}

The results of borehole-side electrical sounding inversion models show that there are obvious electrical differences among rock and soil layers in the study area, which provides conditions for symmetrical quadrupole electrical sounding in this region. Based on the lithological and electrical data of Ningbo Plain, the electrical parameters of each geotechnical layer in the survey area are obtained in Table 1. According to the lithological and electrical characteristics of rock and soil layers in the Yuyao River Valley, they are generalized into five electrical levels. The resistivity of the uppermost level varies greatly due to the influence of the surface. The second level has a low resistivity, less than 8 $\Omega \cdot \mathrm{m}$, corresponding to the silty clay and mucky silty clay. The intermediate level represents the silty sand, fine sand and medium-coarse sand, characterized by a resistivity of 4 to $15 \Omega \cdot \mathrm{m}$. The resistivity of sand gravel and round gravel layers are between 10 and $20 \Omega \cdot \mathrm{m}$, corresponding to the confined aquifers. The bottom bedrock is characterized by resistivity not less than $60 \Omega \cdot \mathrm{m}$.

\subsection{Symmetric quadrupole electrical sounding}

\subsubsection{Symmetric quadrupole electrical sounding diagrams}

The field data of symmetrical quadrupole electrical soundings are inverted and interpreted by the geoelectric analysis software of GeoElectro. Based on the electrical characteristics of rock and soil in the Yuyao River Valley and 13 boreholes in the survey area, the lithology of each electrical layer in the inversion model of symmetrical quadrupole electrical sounding is reasonably inferred. The symmetrical quadrupole electrical sounding inversion models of 7CCD2-7 and 7CCD2-9 were calibrated with the G52 and Cinong42 boreholes, respectively. Geo-electric and geologic interpretation of 7CCD2-7 and 7CCD2-9 are shown in Table 2.

Table 2. Geo-electric and geologic interpretation of symmetrical quadrupole electrical soundings.

\begin{tabular}{cccccc}
\hline & Layer & $\begin{array}{c}\text { Resistivity } \\
(\Omega \cdot \mathrm{m})\end{array}$ & $\begin{array}{c}\text { Thickness } \\
(\mathrm{m})\end{array}$ & $\begin{array}{c}\text { Depth } \\
(\mathrm{m})\end{array}$ & Lithology \\
\hline & R1 & 20 & 1.0 & 0 & fill \\
$7 \mathrm{CCD} 2-$ & $\mathrm{C}$ & 5 & 21.2 & -1.0 & silty clay and mucky silty clay \\
7 & $\mathrm{R} 2$ & 10 & 15 & -22.2 & silty sand \\
& R3 & 17 & 17.3 & -37.2 & round gravel \\
& Rs & 78 & - & -54.5 & bedrock \\
\hline \multirow{2}{*}{$7 \mathrm{CCD} 2-$} & R1 & 16 & 2.3 & 0 & fill \\
9 & $\mathrm{C}$ & 4 & 34 & -2.3 & silty clay and mucky silty clay \\
& R2 & 10 & 11.5 & -36.3 & silty sand and medium-coarse
\end{tabular}




$\begin{array}{lcccc}\text { R3 } & 19 & 13 & -47.8 & \text { sand } \\ \text { Rs } & 69 & - & -60.8 & \text { sand gravel } \\ \text { bedrock }\end{array}$

The 7CCD2-7 electric sounding is $200 \mathrm{~m}$ apart from G52 borehole, and its inversion results are divided into five electrical layers after correction by G52 borehole. The resistivity of surface electrical layer R1 is $20 \Omega \cdot \mathrm{m}$ with the thickness of $1.0 \mathrm{~m}$, which is inferred to be fill. Next, the conductive layer $C$ with the resistivity of $5 \Omega \cdot \mathrm{m}$ and the thickness of $21.2 \mathrm{~m}$ is deduced to be the silty clay and mucky silty clay. The thickness of electric layer R2 is $15 \mathrm{~m}$, corresponding to the silty sand. a resistant layer R3 with $17 \Omega \cdot \mathrm{m}$ and $17.3 \mathrm{~m}$ of thickness corresponds to the round gravel confined aquifer, resting on the resistant substratum Rs.

The 7CCD2-9 electric sounding is $260 \mathrm{~m}$ away from Cinong42 borehole, and its inversion results can be generalized into five electrical layers after corrected by Cinong 42 borehole. The resistivity of the upper electrical layer R1 is $16 \Omega \cdot \mathrm{m}$ and with the thickness of $2.3 \mathrm{~m}$, which is inferred to be surface miscellaneous fill. Under this layer of, a conductive layer $\mathrm{C}$ with $4 \Omega \cdot \mathrm{m}$ and $34 \mathrm{~m}$ of thickness corresponds to the silty clay and mucky silty clay. The resistivity of the intermediate layer $\mathrm{R} 2$ is $10 \Omega \cdot \mathrm{m}$ and its thickness is $11.5 \mathrm{~m}$ which is presumed to be the silty sand and medium-coarse sand. Below, a resistant layer R3 of $19 \Omega \cdot \mathrm{m}$ and $13 \mathrm{~m}$ of thickness corresponds the sand gravel confined aquifer. The burial depth of Rs is $-60.8 \mathrm{~m}$ and the resistivity is more than $69 \Omega \cdot \mathrm{m}$.

\subsubsection{Geo-electric sections}

Five geo-electric sections are established based on the interpretation of the 77 symmetrical quadrupole electrical soundings and lithology, in order to obtain the relationship between lithology and electricity in the study area and determine the distribution of confined aquifers.

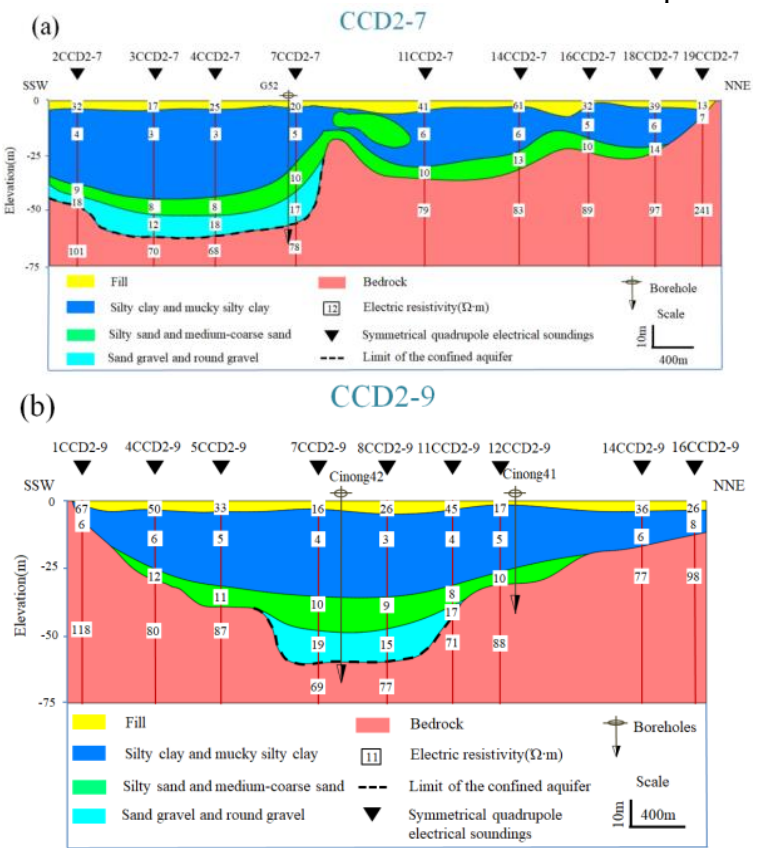

Figure 3. Geo-electric sections CCD2-7 and CCD2-9
The CCD2-7 geo-electric section (Fig. 3a) contains 19 symmetrical quadrupole electrical soundings, which are perpendicular to the Yuyao River Valley and have a total length of about $6100 \mathrm{~m}$. Based on the northern boundary of the confined aquifers, the CCD2-7 section is divided into two regions. One area is located in the south of the section is characterized by thick Quaternary sediments. According to the lithology revealed by G52, the thickness of Quaternary sediments can reach $35 \mathrm{~m}$. The resistivity of the confined aquifers is between 10 and $20 \Omega \cdot \mathrm{m}$, corresponding to the sand gravel and round gravel, which are buried between -62 and $-25 \mathrm{~m}$ in depth and over $2400 \mathrm{~m}$ in width. The other area is located in the north of the CCD2-7 section, which does not contain confined aquifers. The Quaternary overburden is unevenly distributed and the bedrock burial depth gradually becomes shallow along the north.

The CCD2-9 section (Fig. 3b) consists of 16 symmetrical quadrupole electrical soundings, with a total length of $4750 \mathrm{~m}$, located on the right side of the Yuyao River Valley. According to the position of sand gravel and round gravel confined aquifers, the CCD2-9 section is divided into three regions. In the southern area, there is no confined aquifer, and bedrock outcrops at 1CCD2-9 (near Siming Mountain). In the confined aquifer area, the Quaternary overburden is thicker and the thickness of confined aquifers varies greatly. The resistivity of confined aquifers is between 10 and $20 \Omega \cdot \mathrm{m}$, which are buried between -60 and $-40 \mathrm{~m}$ in depth and over $1300 \mathrm{~m}$ in width. In the northern area, it is characterized by the absence of confined aquifers. The Quaternary sediment thickness is smaller than that in the confined aquifer distribution area, and gradually decreases along the north.

The results of five geo-electric sections show that the confined aquifers in the study area correspond to the sand gravel and round gravel with the resistivity of 10 to 20 $\Omega \cdot \mathrm{m}$. The confined aquifers mainly distribute along the middle line of the valley, with a depth between -62 and $-25 \mathrm{~m}$ and a width of more than $1000 \mathrm{~m}$.

\subsubsection{Electrical resistivity profiles}

Five electrical resistivity profiles were established by two-dimensional inversion of five lines in the study area using the geoelectric analysis software of GeoElectro, in order to determine the spatial distribution of the confined aquifers in the Yuyao River valley.

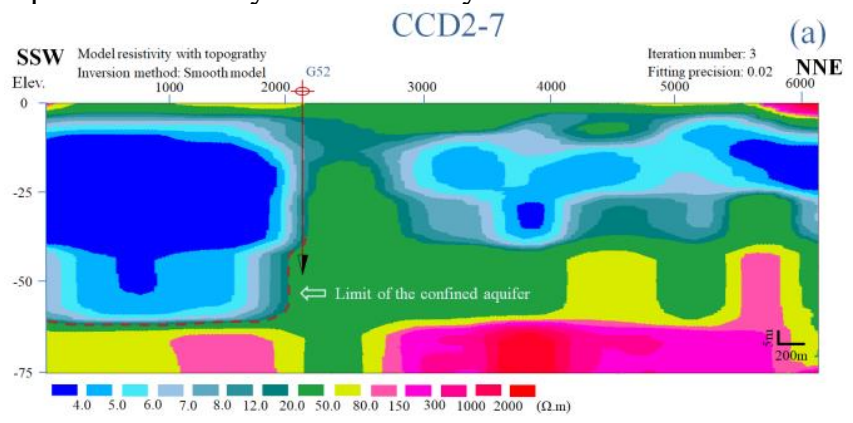




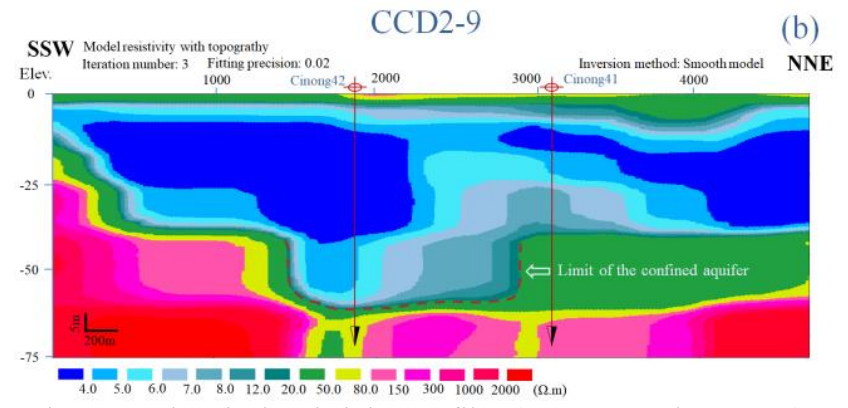

Figure 4. Electrical resistivity profiles (CCD2-7 and CCD2-9) in the study area

The CCD2-7 profile (Fig. 4a) is realized perpendicular to the Yuyao River Valley, and extends in the SSW-NNE direction. It is obtained by two-dimensional inversion from 19 symmetrical quadrupole electrical soundings distributed on the CCD2-7 survey line. The inversion depth and length are $75 \mathrm{~m}$ and $6100 \mathrm{~m}$ respectively. After calibration with G52 borehole, the corresponding relationship between the two-dimensional inversion resistivity and lithology is established. The CCD2-7 profile is interpreted as follows. The resistivity of the surface fill varies from 10 to 100 $\Omega \cdot \mathrm{m}$, and the thickness distribution is uneven. The silty clay and mucky silty clay are characterized by low resistivity (less than $6 \Omega \cdot \mathrm{m}$ ) and large thickness (up to 40 $\mathrm{m}$ locally). The sand layer is a transition layer, resistivity value is between upper and lower layers, and thickness distribution is uneven. The sand gravel and round gravel corresponds to the confined aquifers with the resistivity between 10 and $20 \Omega \cdot \mathrm{m}$ and above high resistivity bedrock whose resistivity exceeding $50 \Omega \cdot \mathrm{m}$. Combining with the resistivity of profile and formation lithology, it can be inferred that the width of confined aquifers is not less than $2200 \mathrm{~m}$, mainly distributed in the depth range of -60 to $-40 \mathrm{~m}$.

The CCD2-9 profile (Fig. 4b) consists of 16 symmetrical quadrupole electrical soundings, located on the west side of the Yuyao River valley, moving towards SSW-NNE. The inversion depth and length are $75 \mathrm{~m}$ and $4750 \mathrm{~m}$, respectively. After calibration with Cinong 42 and Cinong 41 boreholes, the following interpretation is given. The surface fill has a wide range of resistivity variations due to many interference factors near the surface. The resistivity of the silty clay and mucky silty clay is less than $6 \Omega \cdot \mathrm{m}$ and widely distributed in the depth range of -40 to $-10 \mathrm{~m}$. The sand layer is located between clay and gravel layers with a resistivity of $6-12$ $\Omega \cdot \mathrm{m}$. The sand gravel and round gravel confined aquifers with a resistivity between 10 and $20 \Omega \cdot \mathrm{m}$, rests on the bottom high resistivity bedrock. Combining with the resistivity and formation lithology, it is inferred that the confined aquifers are buried between -60 and $-45 \mathrm{~m}$ in depth and about $1300 \mathrm{~m}$ in width.

The results of the 5 electrical resistivity profiles have been calibrated by boreholes in the survey area. It shows that the existence of the confined aquifers in the Yuyao River Valley. The confined aquifers correspond to sand gravel and round gravel with a resistivity between 10 and $20 \Omega \cdot \mathrm{m}$. Based on the interpretation of electrical resistivity profiles and lithology, it is inferred that the confined aquifers in the study area mainly distributes along the middle line of the valley, with the burial depth ranging from -65 to $-30 \mathrm{~m}$ and the width exceeding 1000 $\mathrm{m}$.

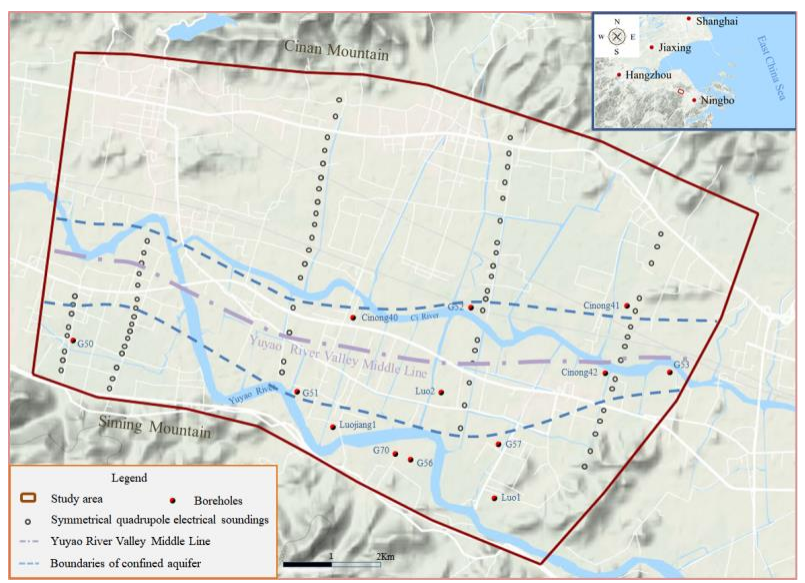

Figure 5. Distribution map of confined aquifers in the study area.

The results of the symmetric quadrupole electrical soundings and borehole-side electrical sounding measurements confirm that the resistivity values of each geotechnical layer in the study area have significant differences in the vertical direction. After calibration with boreholes, it allows attributing the sand gravel and round gravel layers whose resistivity is between 10 and $20 \Omega \cdot \mathrm{m}$ to the confined aquifers. The confined aquifers in the study area were determined to be zonally distributed along the middle line of the valley, with buried depth ranging from -65 to $-25 \mathrm{~m}$ and width exceeding $1000 \mathrm{~m}$ (Fig. 5).

\section{Discussion}

Resistivity is an important physical property of rock and soil, and one of the most important parameters in geophysical measurement, especially in the field of electrical prospecting. It is affected by many factors, such as mineral composition, water content, composition structure and porosity. Symmetric quadrupole electrical sounding is one of the common electrical sounding methods, which is widely used in hydrogeology, engineering geology and coalfield geology. Its principle is based on the difference of electrical properties of underground rock and soil. It solves related geological problems by studying the distribution of natural or artificial electric fields in underground half space.

In order to obtain accurate results, it is necessary to combine various methods. Because the results and explanations of each method can provide reference for other methods, at the same time, they can complement, correct and evaluate each other. In this paper, the distribution of the sand gravel and round gravel layers in the Yuyao River Valley is determined by combining the existing hydrogeological data, borehole-side electrical sounding measurements and symmetrical quadrupole electrical soundings, and the spatial distribution characteristics of the confined aquifers in the study area 
are reasonably inferred.

\section{Conclusions}

The spatial distribution of the confined aquifers in the Yuyao River Valley is determined by combining the symmetrical quadrupole electrical sounding method with the hydrogeological data. Firstly, the geological and hydrological data show that the lithology of strata has obvious subsidence characteristics. From top to bottom, the sequence is "fill - silty clay - mucky silty clay - silty sand - medium-coarse sand - sand (round) gravel bedrock". Then, the borehole-side electrical sounding measurements were carried out near 13 boreholes in the survey area, and the results corroborate that the resistivity values of each geotechnical layer in the study area have significant differences in the vertical direction. After calibration with the lithology of the boreholes, the corresponding relationship between formation lithology and resistivity is obtained (Table 2). Finally, 77 symmetrical quadrupole electrical soundings are carried out on five lines perpendicular to the Yuyao River valley. Five geo-electric sections are established based on the interpretation of the 77 symmetrical quadrupole electrical soundings, and five electrical resistivity profiles were obtained by two-dimensional inversion of five survey lines. After being calibrated with boreholes, The spatial distribution characteristics of the confined aquifers are determined by combining the results of the geo-electric sections and electrical resistivity profiles. Thus, the confined aquifers in the Yuyao River Valley were determined to be zonally distributed along the middle line of the valley, with buried depth ranging from -65 to $-25 \mathrm{~m}$ and width exceeding $1000 \mathrm{~m}$ (Fig. 5). These results corroborate the validity of the combination of the symmetrical quadrupole electrical sounding method and hydrogeological data to determine the spatial geometric characteristics of the confined aquifers in geotechnical strata with significant electrical differences.

\section{Acknowledgements}

This study benefited from the financial support of Zhejiang Institute of Hydrogeology and Engineering Geology. We are grateful to the unit for its support and cooperation in providing all the data needed. We would like to thank the Zhejiang Institute of Engineering Survey for providing important data.

\section{References}

1. Sahoo, S., Russo, T.A., Elliott, J., Foster, I. (2017) Machine learning algorithms for modeling groundwater level changes in agricultural regions of the United States. Water Resour. Res., 53: 3878-3895.

2. Lin, J., Ma, R., Hu, Y., Sun, Z., Mccarter, C.P.R. (2018) Groundwater sustainability and groundwater/surface-water interaction in arid Dunhuang Basin, northwest China. Hydrogeol. J., 26:
1559-1572.

3. Motagh, M., Shamshiri, R., Haghshenas Haghighi, M., Wetzel, H.U., Akbari, B., Nahavandchi, H. (2017) Quantifying groundwater exploitation induced subsidence in the Rafsanjan plain, southeastern Iran, using InSAR time-series and in situ measurements. Eng. Geol., 218: 134-151.

4. Hwang, Y.K., Endres, A.L., Piggott, S.D., Parker, B.L. (2008) Long-term ground penetrating radar monitoring of a small volume DNAPL release in a natural groundwater flow field. J. Contam. Hydrol., 97: 1-12.

5. Song, L., Zhu, J., Yan, Q., Kang, H. (2012) Estimation of groundwater levels with vertical electrical sounding in the semiarid area of South Keerqin sandy aquifer, China. J. Appl. Geophys., 83.

6. Sikandar, P., Bakhsh, A., Arshad, M., Rana, T. (2010) The use of vertical electrical sounding resistivity method for the location of low salinity groundwater for irrigation in Chaj and Rachna Doabs. Environ. Earth. Sci., 60: 1113-1129.

7. Hertrich, M. (2008) Imaging of groundwater with nuclear magnetic resonance. Prog. Nucl. Magn. Reson. Spectrosc., 53: 227-248. 